\title{
ACCURACY OF PANORAMIC AND PERIAPICAL RADIOGRAPHS TO ASSESS ROOT RESORPTION AFTER INCISORS INTRUSION: A COMPARATIVE STUDY
}

\author{
Nahla Gomaa $^{1 *}$, Neveen Fakhry ${ }^{2}$, Medhat EL Sakhawy ${ }^{3}$
}

\begin{abstract}
Objective: The aim of this study was to compare the accuracy of root resorption measurement on panoramic and periapical films after intrusion of maxillary incisors using either microimplant anchorage system or archwire of accentuated compensating curve. Subjects and methods: Forty patients with age ranging from 18 to 24 years old, were randomly divided into two groups of 20 each. Each group was divided into 2 equal subgroups of 10 each: Subgroup A: comprised panoramic radiographic findings. Subgroup B: comprised periapical radiographic findings. Maxillary incisors were intruded using mini-implants in group I, and accentuated compensating curve arch wire in group II. Root resorption was examined with panoramic radiographs (subgroup A) and priapical radiographs (subgroup B) taken at pretreatment and postintrusion. Results: Considering panoramic radiograph, root resorption of the upper incisors using the modified four grade ordinal scale showed that group I had 75\% of the teeth classified with score 0 , and root resorption score 1 in $25 \%$. Group II had $60 \%$ of teeth with score 0 and $32.5 \%$ with scores of 1 and just $7.5 \%$ with score 2 . The difference between both groups was significant $(\mathrm{P}<0.05)$. Regarding periapical radiograph the mean amount of root resorption was significantly high in group II compared to group I. Flaring of incisors in group II is more significant than in group I. Conclusion: During taking panoramic radiograph, patient positioning must be checked to decrease error. Periapical film is preferred in cases when root resorption is expected with significant degrees.
\end{abstract}

KEYWORDS: Root resorption, Panorama, Periapical radiograph.

\section{INTRODUCTION}

Overbite can be defined as "upper anterior teeth overlapping over the lowers, in vertical plane". Overbite is considered deep if lower incisal edges became beyond the maxillary incisor cingulum ${ }^{(1)}$. One of the objectives of orthodontic treatment is to achieve normal overbite as it affects esthetic and function and it is considered as a common feature of a lot of malocclusions ${ }^{(2,3)}$. Treatment modalities of deep overbite correction can be achieved either by intrusion of incisors, extrusion of buccal segments with slight intrusion and some incisors proclination, or a combination of both ${ }^{(3,4)}$. One of the most common complication of orthodontic treatment is the" apical root resorption". Maxillary incisors are the most affected teeth by root resorption because more stress is concentrated on their apecies due to their root characteristics, followed by mandibular incisors and first molars. Using graded scales, root resorption can be classified either minor or moderate

1. Assistant Professor of Orthodontics, Faculty of Dentistry Tanta University, Egypt.

2. Lecturer of Orthodontics, Faculty of Dentistry Tanta University, Egypt.

3. Professor of Orthodontics, Faculty of Dentistry Tanta University, Egypt.

-Corresponding author: nahlag71@yahoo.com 
as usually 1- $2 \mathrm{~mm}^{(5)}$ for upper incisors are resorped, while sever resorption is defined as $4 \mathrm{~mm}$ or more shortening of root length , or more than one-third of the total tooth length, is found in $1 \%$ to $5 \%$ of teeth ${ }^{(6,7)}$. Factors causing root resorption can be classified into: patient-related risk factors and orthodontic treatment- related risk factors ${ }^{(8)}$. Patient-related risk factors include: genetic influences; previous history to root resorption; tooth-root length, morphology and roots with developmental abnormalities. While systemic factors including drugs (nabumetone), hormone deficiency, hypothyroidism, hypopituitarism, asthma ; root proximity to cortical bone; density of alveolar bone; chronic alcoholism; previous trauma; endodontic treatment; severity and type of malocclusion; patient age and sex ${ }^{(9,10)}$. Risk factors related to orthodontic treatment include: type of appliance, technique and duration of treatment, magnitude of applied force, tooth movement direction, amount of apical displacement and force application method (continuous or intermittent) ${ }^{(11)}$. The first step in orthodontic diagnosis is the radiograph evaluation for pathology detection and to assess development of teeth. Cephalometric and panoramic films are considered as a routine primary pretreatment radiographs. On adult patients, other practitioners prefer a full mouth series, others order both a panoramic film and periapical films, while the majority of general dentists obtain periapical films on adult patients only ${ }^{(12)}$. Advantages of the panoramic film include less exposure to radiation, better patient cooperation, less patient chair time and less operator time. Panoramic film also provides a simple visualization of the entire lower face half (the joints, extending from the lower orbits to the most inferior part of the mandible) ${ }^{(13)}$. Disadvantages of panoramic radiography is the quality of the image that depends on correct patient position and proximity of the desired anatomical structures to the focal trough. The Frankfort plane must be parallel to the floor to achieve the correct position ${ }^{(13)}$. In the vertical dimension, the magnification factor is relatively constant (20-35\% enlargement), while less reliable horizontal mea- surements were found ${ }^{(14)}$. Magnification factor of periapical films is usually less than 5\%.Advantages of periapical films over the panorama is that panoramic images can give fine details and less distortion ${ }^{(15)}$. Therefore, the primary objective of the present study was to compare the accuracy of root resorption measurement on panoramic and periapical films after intrusion of maxillary incisors using either microimplant anchorage system or archwire of accentuated compensating curve.

\section{SUBJECTS AND METHODS}

The present comparative study was performed on the radiographs of 40 Egyptian patients ( sample size was estimated by $\mathrm{G}^{*}$ power, version 3.1 with $90 \%$ power and $5 \%$ significant level) with age ranging from 18 to 24 years old, the majority of them were females ( 4 males and 36 females), seeking orthodontic treatment in Orthodontic Department, Faculty of Dentistry, Tanta University.

Inclusion criteria: 1) Good oral hygiene, 2) Permanent dentition and 3) Class I or II molar relationship with deep overbite related to extruded upper incisors (mostly extraction cases).

Exclusion criteria: 1) Patients who had received any orthodontic treatment, 2) Patients with retained deciduous teeth, 3) Medical or dental contraindications for orthodontic treatment, 4) Systemic condition affecting bone metabolism, 5) History of endodontic treatment in the upper incisors, 6) Root dilacerations or taurodontism, 7) History of root resorption before orthodontic treatment as evidenced on periapical films and 8) History of trauma to maxillary incisors. The design and procedures of the present study were accomplished according to the guidelines published by the Faculty of Dentistry, Tanta University Research Ethics Committee. So, approval for this research was obtained. The following records were taken pre-treatment (T1) after thorough clinical examination with medical and dental history and post-intrusion (T2): extra- oral and intraoral 


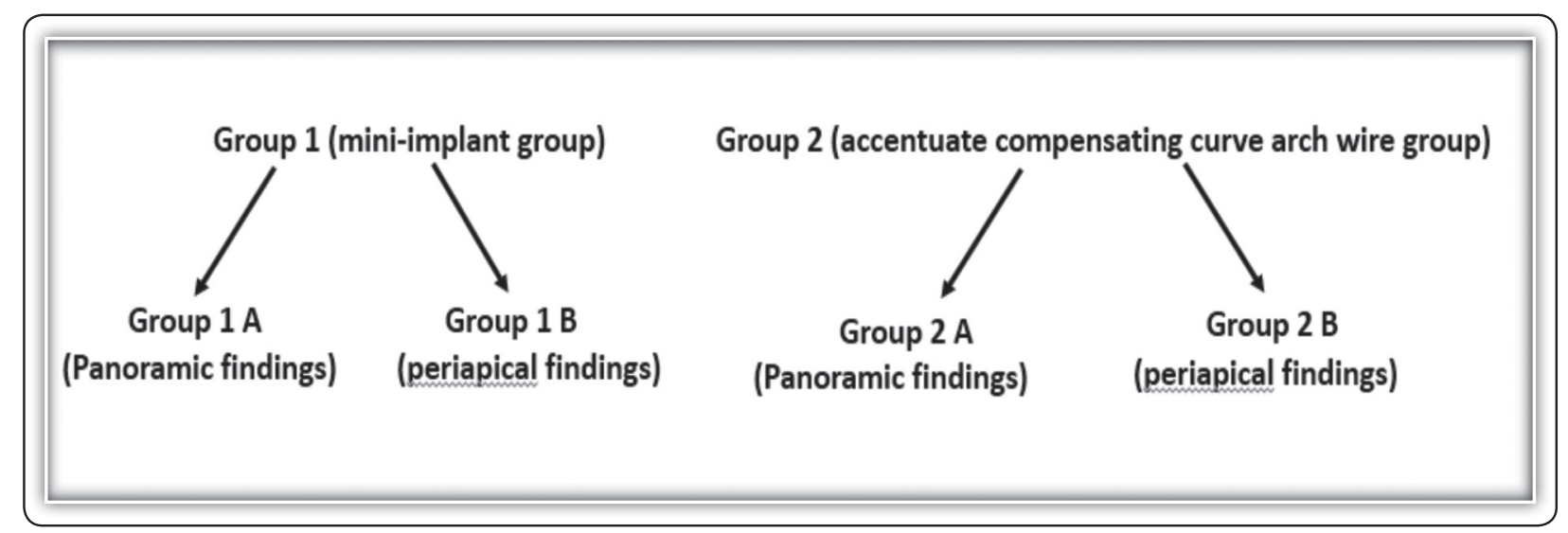

FIG (1) Grouping system

photographs; study models; panoramic x-ray films; lateral cephalometric radiographs and periapical films. All radiographs used in the study were recorded using the same machine for all patients (Pax-i3D Green.15ma, 85kva. Vatech, Korea) with standardized technique. The patients were randomly divided into two groups: Group 1: Consisted of 20 patients (4 males and 16 females) were treated with mini-implants $(1.3-1.6 \mathrm{~mm}$ diameter and $6-8 \mathrm{~mm}$ length) and Group 2: Consisted of 20 female patients were treated with accentuated compensating curve arch wire. Each group were classified according to the radiographic findings into (Fig.1): Group A: comprised panoramic radiographic findings and Group B: comprised periapical radiographic findings.

The patients received hygiene instructions, an informed consent was obtained before placement of the orthodontic appliances and after explaining the treatment procedures in detail to all patients. Every patient received a straight wire Roth appliance (Ormco. USA. $0.022 \times 0.028$ inch slot) which was bonded to the upper teeth. Leveling and alignment was performed by using sequential aligning arch wires until reaching a wire gauge of rectangular $0.016 \times 0.022$ inch stainless steel arch wire. In group I, maxillary incisor intrusion mechanics were carried out by mini-implant anchorage system (AbsoAnchor orthodontic microimplant, Dentos,
South Korea) of 1.3-1.6 mm diameter and 6-8 mm length. Mini-implants were inserted bilaterally in the attached gingivae between maxillary central incisor and lateral incisor. One month after the implantation procedure, intrusion force approximately $80-120 \mathrm{gm}$ ${ }^{(16)}$ was applied on each side on a $0.016 \times 0.022$ inch stainless steel archwire with crimpable hooks distal to the lateral incisors (Fig.2). In group II, maxillary accentuated compensating curve arch wires (round and rectangular) were used in a sequence initiated by $0.016 \mathrm{inch}$, followed by $0.016 \times 0.016 \mathrm{inch}$, $0.016 \times 0.022 \mathrm{inch}$ and finally $0.017 \times 0.025 \mathrm{inch}$ nickel-titanium archwires.

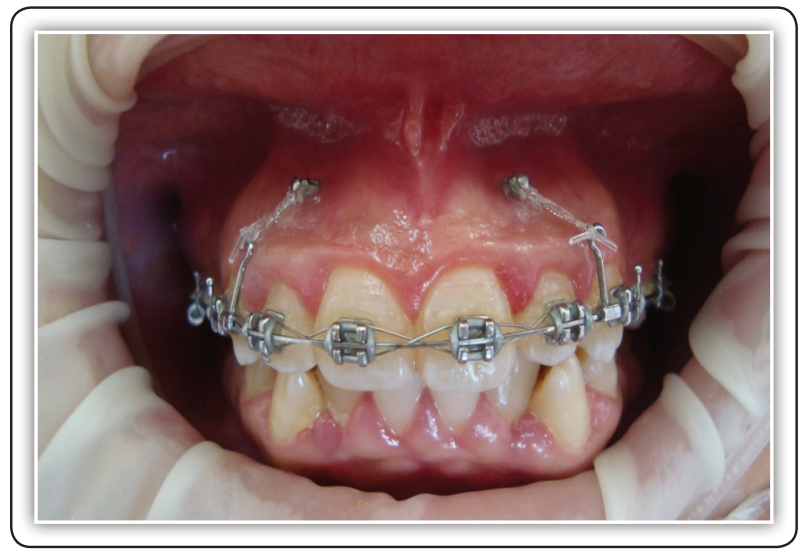

FIG (2) The miniscrews in place with force application 
The T1 and T2 cephalometric radiographs (Table 1, Fig.2) were traced and analyzed by the same coauthor for measuring: 1) SNA, SNB and ANB angles; 2) upper incisor proclination (SN/U1); 3) amount of upper intrusion (PL-CR) from T1 to T2: a linear measurement of upper intrusion is the vertical distance between the incisor centroid (CR) and palatal plane. The CR point was set as $40 \%$ of the distance from the root apex to the alveolar crest. This distance is measured with a caliper which is accurate to the nearest $0.1 \mathrm{~mm}$ and is marked on the long axis of each incisor at T1 then transferred to the $\mathrm{T} 2$ tracing by superimposition on the incisal edge of upper incisor; 4) PL-U6: Vertical distance between the mesiobuccal cusp tip of the maxillary first molar to the palatal plane and 5) Upper tipping (UI-CR): Vertical distance between the maxillary incisal edge to centroid.

TABLE (1): Definitions of cephalometric measurements

\begin{tabular}{|l|l|}
\hline \multicolumn{2}{|c|}{ Cephalometric measurements } \\
\hline 1) SNA $\left({ }^{\circ}\right):$ & $\begin{array}{l}\text { The angle formed by the intersection of } \\
\text { SN and NA. }\end{array}$ \\
\hline 2) SNB $\left({ }^{\circ}\right):$ & $\begin{array}{l}\text { The angle formed by the intersection of } \\
\text { SN and NB. }\end{array}$ \\
\hline 3) ANB $\left({ }^{\circ}\right):$ & $\begin{array}{l}\text { The angle formed by the intersection of } \\
\text { NA and NB. }\end{array}$ \\
\hline 4) SN/U1 $\left({ }^{\circ}\right):$ & $\begin{array}{l}\text { The angle formed by the intersection of } \\
\text { SN and the long axis of upper incisor. }\end{array}$ \\
\hline 5) PL-CR (mm): & $\begin{array}{l}\text { It is the vertical distance between centroid } \\
\text { and palatal plane. }\end{array}$ \\
\hline 5) PL-U6 $(\mathbf{m m}):$ & $\begin{array}{l}\text { Vertical distance between the mesiobuccal } \\
\text { cusp tip of the maxillary first molar to the } \\
\text { palatal plane. }\end{array}$ \\
\hline 6) U1-CR $(\mathbf{m m}):$ & $\begin{array}{l}\text { Vertical distance between the maxillary } \\
\text { incisal edge to centroid. }\end{array}$ \\
\hline
\end{tabular}

\section{Measurement of root resorption:}

Root resorption was examined with panoramic radiographs (group: 1A, 2A) and priapical radiographs (group: 1B, 2B) taken at pretreatment and postintrusion. In groups $1 \mathrm{~A}$ and $2 \mathrm{~A}$, root resorption of the upper incisors was evaluated from

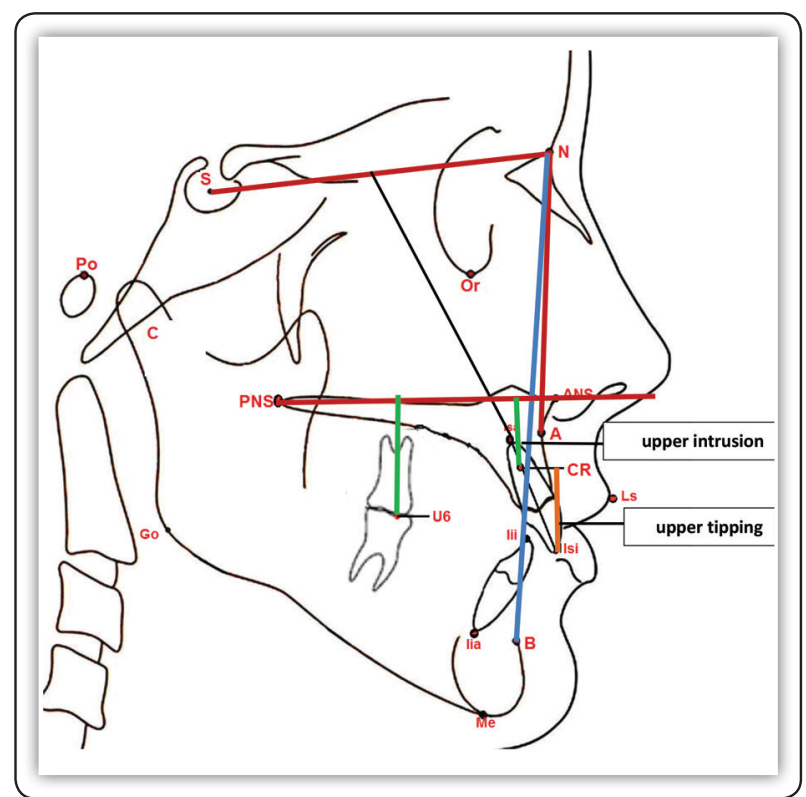

FIG (3) Cephalometric measurements

panoramic radiographs using the modified four grade ordinal scale ${ }^{(17,18)}$ which is as follow: grade 0 , no apical root resorption; grade 1 , mild resorption with slight blunting of root apex; grade 2, moderate resorption with loss of up to one third of root length and grade 3, severe resorption with loss of more than one third of root length. While in groups 1B and $2 \mathrm{~B}$, upper incisor root resorption was detected from periapical radiographs by the subjective score system of Levander and Malmgren, $\mathbf{1 9 8 8}^{[19]}$ classifying it into 5 grades (Fig.3):grade 0, no root resorption; grade 1, mild resorption with normal root length and only irregular contour; grade 2, moderate resorption with small area of root loss and almost straight contour of apex; grade 3 , accentuated resorption with loss of almost one third of root length and grade 4, extreme resorption with loss of more than one third of root length. The resorption score was determined for each tooth; there were 4 evaluations per subject, totaling 80 scores per group regarding groups $1 \mathrm{~A}$ and $2 \mathrm{~A}$ (panoramic radiographs) or groups $1 \mathrm{~B}$ and $2 \mathrm{~B}$ (periapical radiographs). Intra-examiner and inter-examiner reliability were determined by remeasuring the 
radiographs after 2 weeks. Dahlberg error, D, is defined as:

$$
\mathrm{D}=\sqrt{\sum_{i=1}^{N} \frac{d_{i}^{2}}{2 N}}
$$

Where $d_{i}$ is the difference between the first and second measure; $N$ is the sample size which was remeasured. The results were collected, tabulated and statistically analyzed.

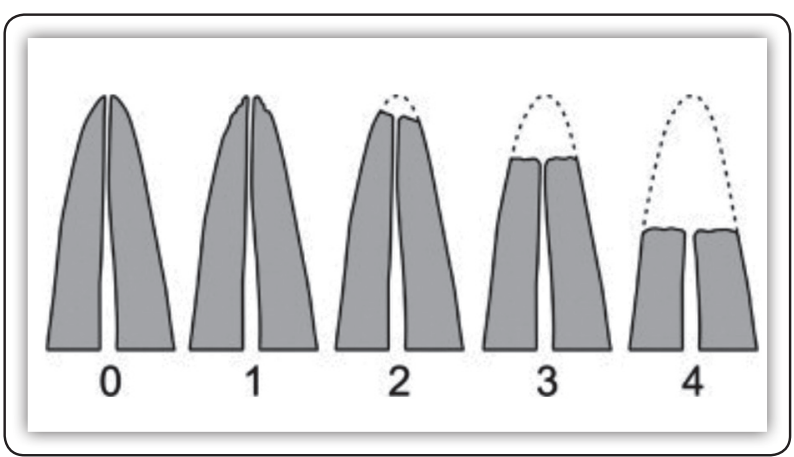

FIG (4) Score system of Levander and Malmgren : grade 0: no root resorption, grade 1: mild resorption - root with normal length and only irregular contour, grade 2: moderate resorption - small area of root loss with apex having almost straight contour, grade 3: accentuated resorption - loss of almost one third of root length, grade 4: extreme resorption - loss of more than one third of root length.

\section{Statistical analysis}

The collected data for the 40 patients was analyzed using SPSS software version ${ }^{(22)}$. The following tests were carried out: $t$. test was applied to compare intrusion time and each pre and post treatment parameters. The Chi-square test was used to calculate the tooth distribution according to the scoring system of the modified four grade ordinal scale and Levander and Malmgren. For assessment of treatment changes within the groups, a paired sample $t$. test was performed. While unpaired $t$. test was used for the evaluation of changes between the groups.

\section{RESULTS}

The present study was carried out on the radiographs of 40 patients from the clinic of the Orthodontic Department, Faculty of Dentistry, Tanta University. Dahlberg error was insignificant. Regarding the intrusion period, maxillary incisor intrusion lasted 6.43 months in group I while 6.74 months in group II with statistically insignificant difference between both groups (Table 1).

TABLE (2): Comparison of the intrusion time (in month) between group I and group II.

\begin{tabular}{|c|c|c|c|c|}
\hline Gps & $\begin{array}{c}\text { Mean of } \\
\text { intrusion time }\end{array}$ & \pm SD & T test & P value \\
\hline GI & 6.43 & \pm 0.87 & $\mathbf{1 . 2 0 3}$ & $\mathbf{0 . 2 3 8}$ \\
\hline GII & 6.74 & \pm 0.76 & & \\
\hline
\end{tabular}

\section{$P>0.05$ (Non significant)}

The results of the present study will be presented under the following topics: The lateral cephalometric radiograph findings, the panoramic radiograph findings and the periapical radigraph findings.

\section{The lateral cephalometric radiograph findings:}

Preintrusion and postintrusion comparison of the cephalometric measured parameters for both groups are evaluated. The lateral cephalometric $\mathrm{x}$ - ray analysis of the angular measurements (SNA, SNB and SN/U1) in group I revealed that there were no significant differences in any measured cephalometric angular variables between pretreatment and post-intrusion stage except ANB angle that showed slight significant change $(\mathrm{P}<0.05)$. Also, there were insignificant differences in the sagittal skeletal measurements (SNA, SNB and ANB angles) in group II. While the findings of the SN/U1 angle revealed a significant increase $(\mathrm{P}<0.05)$ of the labial inclination (flaring) of upper incisors in group II. The cephalometric analysis of the linear measurements (PL-CR, PL-U6 and U1$\mathrm{CR}$ ) in group I showed that there was a significant 
change in the vertical position of the CR (PL-CR; upper intrusion) $(\mathrm{P}<0.05)$. However, there were insignificant differences in the vertical position of the maxillary first molars (PL-U6) and U1-CR (upper tipping). Regarding group II, the results showed a high significant decrease of U1-CR distance $(\mathrm{P}<0.001)$ and non-significant decrease of PL-CR distance (upper intrusion). Meanwhile, no significant difference of PL-U6 distance was observed after intrusion period in group II. On evaluating cephalometric angular measurements, skeletal variables SNA, SNB and ANB changes did not show any significant differences between group I and group II. There was high significant greater increase in $\mathrm{SN} / \mathrm{U} 1$ angle $(\mathrm{P}<0.001)$ in group II than in group I. In the same vein, when considering the amount of intrusion of the maxillary incisors (PL-CR) in both groups, it was greater in group I than in group II insignificantly. Moreovwe, the vertical position of the maxillary first molars (PLU6) showed insignificant differences between the studied groups. The maxillary incisors tipped more labially in group II compared with group I which represented by high significant decrease of U1-CR distance $(\mathrm{P}<0.001)$ in group II more than in group I (Table 2).

TABLE (3): Comparison of the cephalometric mean changes between group I and group II.

\begin{tabular}{|c|c|c|c|c|c|}
\hline \multirow{8}{*}{ 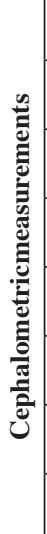 } & & GI & GII & t. test & p. value \\
\hline & SNA $\left(^{\circ}\right)$ & $-1.27 \pm 0.24$ & $-1.19 \pm 0.13$ & 1.309 & 0.198 \\
\hline & SNB $\left(^{\circ}\right)$ & $0.50 \pm 0.23$ & $0.41 \pm 0.19$ & 1.349 & 0.185 \\
\hline & ANB $\left({ }^{\circ}\right)$ & $-1.57 \pm 0.23$ & $-1.43 \pm 0.29$ & 1.693 & 0.099 \\
\hline & SN/U1 $\left({ }^{\circ}\right)$ & $1.59 \pm 0.14$ & $8.30 \pm 2.61$ & 11.479 & $0.001 * *$ \\
\hline & PL-CR (mm) & $-1.61 \pm 0.26$ & $-1.44 \pm 0.28$ & 1.991 & 0.054 \\
\hline & PL-U6 (mm) & $-0.09 \pm 0.08$ & $-0.05 \pm 0.06$ & 1.786 & 0.082 \\
\hline & U1-CR (mm) & $-0.45 \pm 0.20$ & $-2.18+0.78$ & 8.956 & $0.001 * *$ \\
\hline
\end{tabular}

$P>0.05$ (Non significant), $* * p \leq 0.001$ (Highly significant)

\section{The panoramic radiograph findings:}

Considering evaluation of root resorption of the upper incisors from panoramic radiographs using the modified four grade ordinal scale (Table 3), the obtained results showed that group I had $75 \%$ of the teeth classified with score 0 and only $25 \%$ had root resorption score of 1 . Group II had $60 \%$ and $32.5 \%$ of the teeth with scores of 0,1 respectively and just $7.5 \%$ with score 2 . The difference between the two studied groups was significant $(\mathrm{P}<0.05)$.

TABLE (4): Root resorption score by the modified four grade ordinal scale ${ }^{(15,16)}$ in group I and group II.

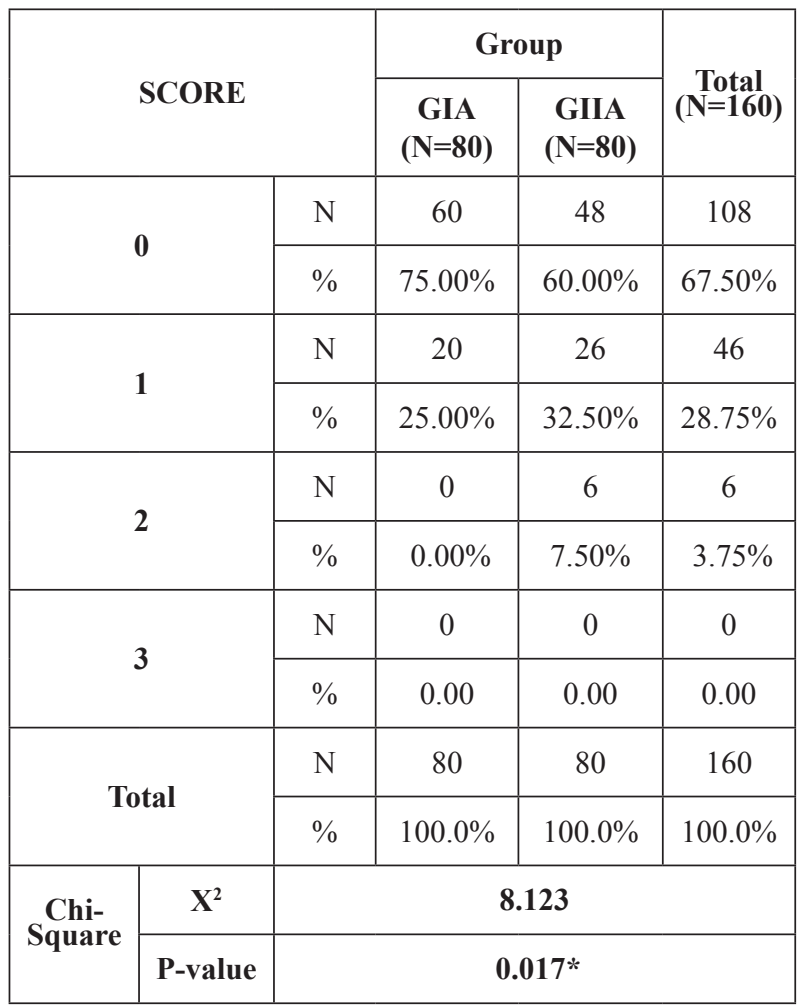

$* p \leq 0.05$ (significant)

\section{The periapical radiograph findings:}

It was noticed that group I had $12.5 \%$ of the teeth classified with score 0 and the remaining $87.5 \%$ had root resorption score of 1 and 2 (Table 4). Group II had $98.75 \%$ of the teeth with scores of 0,1 and 2 , while only $1.25 \%$ with score 3 . The difference between the two studied groups was highly significant $(\mathrm{P}<0.001)$. 
TABLE (5): Root resorption score of Levander and Malmgren ${ }^{(17)}$ in group I and group II.

\begin{tabular}{|c|c|c|c|c|c|}
\hline & & & & oup & \\
\hline & SCORE & & GIB & GIIB & $(\mathrm{N}=160)$ \\
\hline & & $\mathrm{N}$ & 10 & 0 & 10 \\
\hline & & $\%$ & $12.50 \%$ & 0.00 & $6.25 \%$ \\
\hline & & $\mathrm{N}$ & 45 & 34 & 79 \\
\hline & & $\%$ & $56.25 \%$ & $42.50 \%$ & $49.37 \%$ \\
\hline & & $\mathrm{N}$ & 25 & 44 & 69 \\
\hline & & $\%$ & $31.25 \%$ & $55.00 \%$ & $43.12 \%$ \\
\hline & & $\mathrm{N}$ & 0 & 2 & 2 \\
\hline & & $\%$ & 0.00 & $2.50 \%$ & $1.25 \%$ \\
\hline & & $\mathrm{N}$ & 0 & 0 & 0 \\
\hline & & $\%$ & 0.00 & 0.00 & 0.00 \\
\hline & & $\mathrm{N}$ & 80 & 80 & 160 \\
\hline & & $\%$ & $100.0 \%$ & $100.0 \%$ & $100.0 \%$ \\
\hline Chi- & $\mathbf{X}^{2}$ & & & .759 & \\
\hline & P-value & & & $01 \%$ & \\
\hline
\end{tabular}

$* * p \leq 0.001$ (Highly significant)

\section{Comparison of root resorption score system on panoramic vs periapical radiographs in group I:}

Considering difference in grades between the two score systems that used in evaluation of root resorption on both panoramic (4 grades: $0-3)$ and periapical radiographs (5 grades: 0-4), comparison was carried out between similar grades in both types of radiographs in group I (Table 5). Regarding score 0 in both panoramic (GIA) and periapical (GIB) evaluations, $75 \%$ and $12.5 \%$ of the teeth respectively showed no evidence of root resorption on both types of radiographs. On evaluating grades that express root resorption less than one third of root length, $25 \%$ of the teeth classified with score 1 on panoramic radiographs, while $87.5 \%$ with scores 1 and 2 collectively on periapical radiographs. The difference between the two studied groups was highly significant $(\mathrm{P}<0.001)$.
TABLE (6): Comparison of root resorption score system on panoramic vs periapical radiographs in group I.

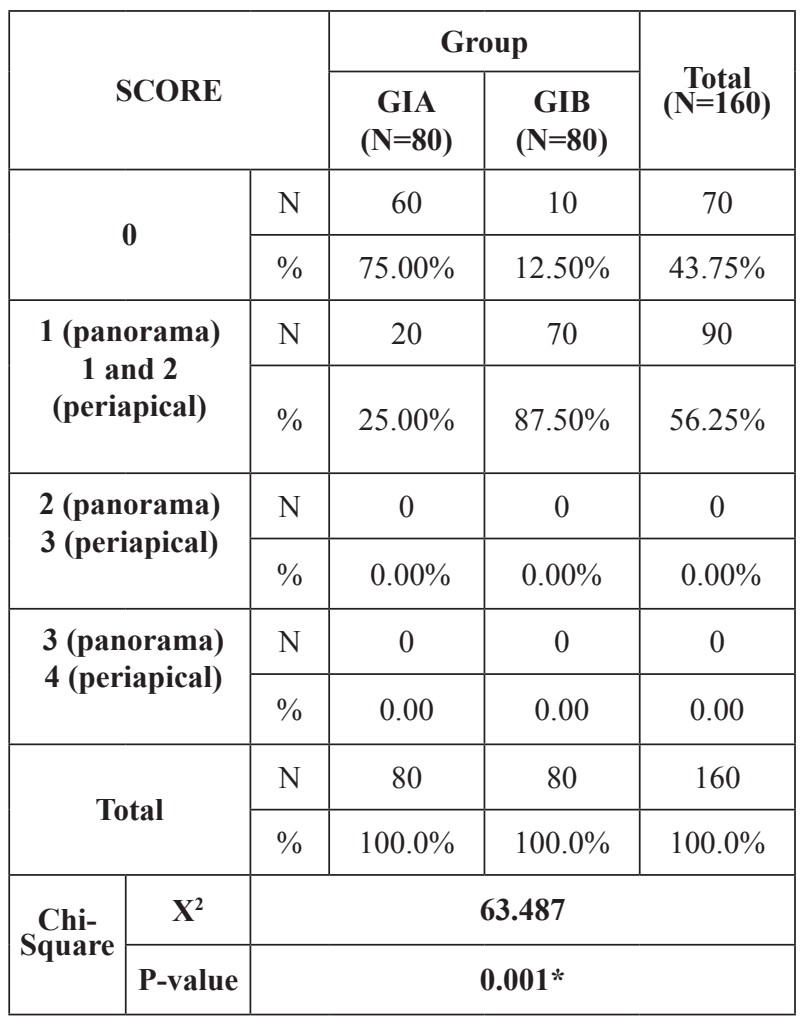

$* * p \leq 0.001$ (Highly significant)

Comparison of root resorption score system on panoramic vs periapical radiographs in group II:

As was done for the comparison between similar grades in both types of radiographs in group I, that for group II (Table 6) and the results revealed that regarding score 0 in both panoramic (GIIA) and periapical (GIIB) evaluations, $60 \%$ and $0 \%$ of the teeth respectively showed no evidence of root resorption on both types of radiographs. While, on evaluating grades that express root resorption less than one third of root length, $32.5 \%$ of the teeth classified with score 1 on panoramic radiograph and $97.5 \%$ with scores 1 and 2 collectively on periapical radiograph. In the same vein, on evaluating grades that express root resorption up to one third of root length, $7.5 \%$ of the teeth classified with score 2 on panoramic radiographs and only $2.5 \%$ with scores 3 
on periapical radiographs. The difference between the two studied groups was highly significant $(\mathrm{P}<$ $0.001)$.

TABLE (7): Comparison of root resorption score system on panoramic vs periapical radiographs in group II.

\begin{tabular}{|c|c|c|c|c|c|}
\hline \multirow{2}{*}{\multicolumn{3}{|c|}{ SCORE (periapical) }} & \multicolumn{2}{|c|}{ Group } & \multirow{3}{*}{$\begin{array}{c}\begin{array}{c}\text { Total } \\
(\mathbf{N}=\mathbf{1 6 0})\end{array} \\
48\end{array}$} \\
\hline & & & \multirow{2}{*}{$\begin{array}{c}\begin{array}{c}\text { GIIA } \\
(\mathbf{N}=\mathbf{8 0})\end{array} \\
48\end{array}$} & \multirow{2}{*}{$\begin{array}{c}\begin{array}{c}\text { GIIB } \\
(\mathbf{N}=\mathbf{8 0})\end{array} \\
0\end{array}$} & \\
\hline \multirow{2}{*}{\multicolumn{2}{|c|}{$\mathbf{0}$}} & $\mathrm{N}$ & & & \\
\hline & & $\%$ & $60.00 \%$ & 0.00 & $30.00 \%$ \\
\hline \multirow{2}{*}{\multicolumn{2}{|c|}{$\begin{array}{c}1 \text { (panorama) } \\
1 \text { and } 2 \\
\text { (periapical) }\end{array}$}} & $\mathrm{N}$ & 26 & 78 & 104 \\
\hline & & $\%$ & $32.50 \%$ & $97.50 \%$ & $65.00 \%$ \\
\hline \multirow{2}{*}{\multicolumn{2}{|c|}{$\begin{array}{l}2 \text { (panorama) } \\
3 \text { (periapical) }\end{array}$}} & $\mathrm{N}$ & 6 & 2 & 8 \\
\hline & & $\%$ & $7.50 \%$ & $2.50 \%$ & $5.00 \%$ \\
\hline \multirow{2}{*}{\multicolumn{2}{|c|}{$\begin{array}{l}3 \text { (panorama) } \\
4 \text { (periapical) }\end{array}$}} & $\mathrm{N}$ & 0 & 0 & 0 \\
\hline & & $\%$ & 0.00 & 0.00 & 0.00 \\
\hline \multirow{2}{*}{\multicolumn{2}{|c|}{ Total }} & $\mathrm{N}$ & 80 & 80 & 160 \\
\hline & & $\%$ & $100.0 \%$ & $100.0 \%$ & $100.0 \%$ \\
\hline \multirow{2}{*}{$\begin{array}{l}\text { Chi- } \\
\text { Square }\end{array}$} & $\mathbf{X}^{2}$ & \multicolumn{4}{|c|}{76.001} \\
\hline & P-value & \multicolumn{4}{|c|}{$0.001 *$} \\
\hline
\end{tabular}

$* * p \leq 0.001$ (Highly significant)

\section{DISCUSSION}

The common findings at the end of orthodontic treatment is the apical root resorption. Various degrees of root resorption can be noticed. The most severe form of root resorption occurs when shortening of root is more than one-third or more than $4 \mathrm{~mm}$ of the total tooth length ${ }^{(20)}$. In this study comparison of the accuracy of root resorption measurement on panoramic and periapical films after intrusion of maxillary incisors using either microimplant anchorage system or archwire of accentuated compensating curve was done. Advantages of panoramic films include more patient convenience, less radiation dose and time- saving ${ }^{(21)}$. Details of the alveolar bone and root can be obtained from periapical films ${ }^{(22,23)}$. CR of the central incisor was the reference point of choice as it can be easily identified, has high reproducibility and it is unaffected by the change in tooth inclination ${ }^{(24)}$. Results of present study considering root resorption of the upper incisors from panoramic radiographs using the modified four grade ordinal scale (Table 5), showed that group I had $75 \%$ of the teeth classified with score 0 , and root resorption score 1 in $25 \%$. Group II had $60 \%$ of teeth with score 0 and $32.5 \%$ with scores of 1 and just $7.5 \%$ with score 2 . The difference between both groups was significant $(\mathrm{P}<0.05)$. Considering periapical radiograph the mean amount of root resorption was significantly high in group II compared to group I. Incisor flaring occurred in group II more significantly than in group I. Hence, it is suggested that the increasing amount of root resorption in group (II) can be related to incisor flaring during intrusion ${ }^{(25)}$. Evaluation of root resorption on panoramic and periapical radiographs was done by using difference in grades between two score systems, comparison was carried out between similar grades in both types of radiographs in group I. The difference between the both groups was highly significant $(\mathrm{P}<0.001)$. Comparison of root resorption score system on panoramic vs periapical radiographs in group II showed that the difference between the two studied groups was highly significant $(\mathrm{P}<0.001)$. Sameshima and Asgarifar ${ }^{(26)}$ evaluated accuracy of periapical and panoramic radiographic films to assess the amount of root resorption. They found a significant higher apical root resorption in panoramic films compared to periapical films. They added that panoramic films exaggerate amount of root resorption by $20 \%$ or more. Ahuja et al; ${ }^{(21)}$ also agree with results of present study. Evaluation of root resorption assessment was done by using panoramic films compared to periapical films. They concluded that assessment of shape and resorption of the root is much harder in panoramic radiographs. Panoramic film can be as diagnostic as a set of periapical 
films if it is well taken, although it has low density, low contrast, much laboratories and machines variability and positioning errors. So, if panoramic film is hard to read or distorted in same region, the problem can be discussed and resolved with the technician ${ }^{(27)}$. Other studies also concluded that a greater error cause in panoramic film was the patient positioning rather than intermachine variance ${ }^{(28-30)}$. Results of the present study revealed that inspite of advantages of panoramic radiography, exaggeration of root resorption and difficulty to assess root shape compared to periapical films were found.

\section{CONCLUSION}

Panoramic film is considered as an initial diagnostic radiographic record in orthodontics. Patient positioning must be checked to decrease error during taking panoramic radiograph.

Periapical film is preferred in cases when root resorption is expected with significant degrees.

\section{REFERENCES}

1. Hans MG, Kishiyama CH, Parker SH, Wolf GR, Noachtar R: Cephalometric evaluation of two treatment strategies for deep overbite correction. Angle Orthod. 1994; 64:265-74.

2. Al-Buraiki H, Sadowsky C, Schneider B. The effectiveness and long-term stability of overbite correction with incisor intrusion mechanics. Am J Orthod Dentofacial Orthop.2005; 127:47-55.

3. Saxena R, Kumar PS, Upadhyay M, Naik V. A clinical evaluation of orthodontic mini-implants as intraoral anchorage for the intrusion of maxillary anterior teeth. World J Orthod. 2010; 11:346-51.

4. Chen Y, Yao C, Chang H. Nonsurgical correction of skeletal deep overbite and class II division 2 malocclusion in an adult patient. Am J Orthod Dentofacial Orthop.2004; 126:371-78.

5. Killiany DM: Root resorption caused by orthodontic treatment: review of literature from 1998 to 2001 for evidence. Prog Orthodm. 2002; 3: 2-5.

6. Kook YA, Park S, Sameshima GT. peg shaped and small lateral incisors not at higher risk for root resorption. Am J Orthod Dentofacial Orthop.2003; 123:253-8.
7. Remington DN, Joondeph DR, Arthun J, Riedel RA, Chapko MK. Long-term evaluation of root resorption occurring during orthodontic treatment. Am J Orthod Dentofacial Orthop.1989; 96: 43-6.

8. Chan E, Darendeliler MA. Physical properties of root cementum: Part 7. Extent of root resorption under areas of compression and tension. Am J Orthod Dentofacial Orthop.2006; 129: 504-10.

9. Thailander B, Rygh P, Reitan K. Tissue reactions in orthodontics. In: Graber TM, Vanarsdall RL, VIG KW, editors. Orthodontics: current principles and techniques. 4th ed. St Louis: C.V. Mosby.2005.

10. Pandis N, Nasika M, Polychronopoulou A, Eliadies T. External apical root resorption in patients treated with conventional and self-ligating brackets. Am J Orthod Dentofacial Orthop.2008; 134: 646-51.

11. Scott P, DiBiase AT, Sherriff M, Cobourne MT. Alignment of efficiency of Damon 3 self-ligating and conventional orthodontic bracket systems: a randomized clinical trial. Am J Orthod Dentofacial Orthop.2008; 134: 470-8.

12. Haring JI, Jansen L. Dental Radiology: Principles and Techniques. 2nd ed. Philadelphia, Penn: WB Saunders; 2000:342-62.

13. Wyatt DL, Farman AG. Accuracy of dimensional and angular measurements from panoramic and lateral oblique radiographs. Dentomaxillofac Radiol. 1994; 24:225-31.

14. Glenn T., Kati O. Assessment of Root Resorption and Root Shape: Periapical vs Panoramic Films. Angle Orthod 2001; 71:185-9.)

15. Rohlin M, Kullendorff B, Ahlqwist M, Henrikson CO, Hollender L, Stenstrom B. Comparison between panoramic periapical radiography in the diagnosis of periapical bone lesions. Dentomaxillofac Radiol. 1989; 18:151-5.

16. Deguchi T, Murakami T, Kuroda S, Yabuuchi T, Kamioka $\mathrm{H}$, Yamamoto T: Comparison of the intrusion effects on the maxillary incisors between implant anchorage and Jhook headgear. Am J Orthod Dentofacial Orthop. 2008; 133: 654-60.

17. Sharpe W, Reed B, Subtelny JD. Poison A. Orthodontic relapse, apical root resorption and crestal alveolar bone levels. Am J Orthod Dentofacial Orthop.1987; 91:252-8.

18. McNab S, Battistutta D, Taveme A, Symons AL. External apical root resorption following orthodontic treatment. Angle Orthod 2000; 70:227-32.

19. Levander E, Malmgren O. Evaluation of the risk of root resorption during orthodontic treatment: a study of upper incisors. Eur J Orthod. 1988; 10:30-8. 
20. Copeland S, Green L. Root resorption in maxillary central incisors following active orthodontic treatment. Am J Orthod Dentofacial Orthop.1986; 89:51-5.

21. Ahuja P, Mhaske S, Mishra G, Bhardwaj A, Dwivedi R, Mangalekar S. Assessment of Root Resorption and Root Shape by Periapical and Panoramic Radiographs: A Comparative Study. J Contemp Dent Pract 2017; 18(6):479-83.

22. Bruks A, Enberg K, Nordqvist I, Hansson AS, Jansson L, Svenson B. Radiographic examinations as an aid to orthodontic diagnosis and treatment planning. Swedish Dent J. 1999; 23:77-85.

23. Atchison KA, Luke LS, White SC. An algorithm for ordering pretreatment orthodontic radiographs. Am J Orthod Dentofac Orthop. 1992:102:29-44.

24. Özsoy ÖP, Özçırpıcı AA, Veziroğlu F. Miniscrews for upper incisor intrusion. European Journal of Orthodontics. 2009; 31: 412-16.
25. Chiquetoa K, Martinsb DR, Jansonc G. Effects of accentuated and reversed curve of Spee on apical root resorption. Am J Orthod Dentofacial Orthop. 2008; 133: 261-68.

26. Sameshima G, Asgarifar K. Assessment of Root Resorption and Root Shape: Periapical vs Panoramic Films. Angle Orthod 2001; 71:185-9.

27. Rushton VE, Horner K, Worthington HV. The quality of panoramic radiographs in a sample of general dental practices. Br Dent J. 1999; 186:630-33.

28. Langland OE, Langlais RP, McDavid WD, DelBalso AM. Panoramic Radiography. 2nd ed. Philadelphia, Penn: Lea \& Febiger; 1989:38-75.

29. Wyatt DL, Farman AG. Accuracy of dimensional and angular measurements from panoramic and lateral oblique radiographs. Dentomaxillofac Radiol. 1994; 24:225-31.

30. Lund TM, Manson-Hing LR. Relation between tooth positions and focal troughs in panoramic machines. Oral Surg. 1975; 40:285-93. 